\title{
Influence of passenger car auxiliaries on pollutant emission factors within the
}

\section{Artemis model}

\author{
Stéphane ROUJOL \& Robert JOUMARD
}

French National Institute for Transport and Safety Research, Lab. Transport and Environment INRETS, case 24, 69765 Bron cedex, France. joumard@inrets.fr

\section{Abstract}

The impact of the auxiliaries and particularly Air Conditioning on emissions $\left(\mathrm{CO}_{2}, \mathrm{CO}, \mathrm{HC}, \mathrm{NOx}\right.$, and particles) is investigated. To this aim, various data from European laboratories are used and analysed. Parameters linked to technology and to climatic conditions are investigated. The main distinction is made between gasoline and diesel vehicles. A physical model is proposed to extrapolate the excess emissions at low temperature (below $28^{\circ} \mathrm{C}$ ) and with solar radiation, together with a statistical model.

Keys-words: Air Conditioning, auxiliary, emission, atmospheric pollutants, passenger car, climatic condition.

\section{Introduction}

The Artemis (Assessment and Reliability of Transport Emission Models and Inventory Systems) study is aiming at developing a harmonised emission model for road, rail, air and ship transport to provide consistent emission estimates at the national, international and regional level. A workpackage is aiming at improving the exhaust emission factors for the passenger cars and light duty vehicles, by enlarging the emission factor database, especially for effects of auxiliaries.

A European Climate Change Programme working group estimated that the usage of air conditioning (AC) systems under average European conditions causes an increase of fuel consumption between 4 and $8 \%$ in 2020 (ECCP, 2003). A recent study valuated an increase of fuel consumption in 2025 below $1 \%$ (Hugrel \& Joumard, 2004). That is why it is proposed to undertake 
a state-of-the-art review of this area, to include fleet characteristics and a collection of data on auxiliaries (Roujol, 2005). Studies about air conditioning have been done in Europe focussed on the evaluation of individual passenger car emission due to AC (Barbusse et al., 1998; Gense, 2000; Pelkmans et al., 2003; Weilenmann et al., 2004), or on the improvement of AC (Benouali et al., 2003). A major study about AC impact has been carried out in the framework of Mobile 6 by the USEPA, focussed on the real use of AC in real conditions (Koupal, 2001) and on the effect of air conditioning running at full load on regulated pollutants (Koupal \& Kremer, 2001).

\section{1 - Excess fuel consumption and $\mathrm{CO}_{2}$ emission data analysis}

Air conditioning database is made up of experimental data from 3 European laboratories (Utac and Cenerg in France, Vito in Belgium), i.e. 27 vehicles and 146 tests. Driving cycle, number of vehicle tests, type of vehicle, experimental objectives vary with experimentation. The choice of vehicles covers the main types of vehicle (small and large vehicles), different propulsion systems (gasoline and diesel) and the emission standards (mainly Euro 1, but also Euro 3 and 4). The climatic conditions are specific to each laboratory, but have been chosen in order to represent severe climatic conditions. The small size of the database allows us to perform a simple statistical analysis. According to Mobile 6, emitter classes, vehicle type, driving cycle, emission AC off and mean speed have to be distinguished to estimate effect of AC. At this short list, we can add, as proposed by Benouali et al. (2003), the regulation type and the compressor technology type.

The excess emission of pollutants due to air conditioning is the difference of emission with and without air conditioning running in the same condition. We have first to decide the type of unit to express the excess fuel consumption due to AC: in volume per distance unit or in volume per time unit. For physical reason (no strong relation between cooling demand and vehicle speed), it seems that volume per time $(1 / \mathrm{h}$ for instance) is better.

According to Figure 1, the mean speed has little impact on excess fuel consumption expressed in $1 / \mathrm{h}$ (with an average increasing from .65 to $.95 \mathrm{l} / \mathrm{h}$ between 19 and $120 \mathrm{~km} / \mathrm{h}$ ), but variance test indicates that the relation is statistically significant. The data can be divided in two parts: i) standard 
driving cycles (UDC, NEDC and EUDC) with low average speed and low load, giving low excess fuel consumption independent of the speed, and ii) 90 and $120 \mathrm{~km} / \mathrm{h}$ constant speed driving cycles with higher speed and load, giving higher excess fuel consumption. In the case of standard cycles, the effect of AC on fuel consumption is partially hidden by the improvement of engine efficiency, because the AC running increases the load and therefore the engine efficiency. But for real driving cycles and for the 90 and $120 \mathrm{~km} / \mathrm{h}$ constant speed, engine load is slightly higher and the AC running does not increase the engine efficiency. A similar conclusion is given in a recent experimental study on two vehicles in real driving conditions (Roumégoux et al., 2004). Globally, for real driving cycle, fuel consumption due to AC expressed in $1 / \mathrm{h}$ should be quite independent of the speed or type of driving cycle.

Technological parameters analysed are parameters connected to the vehicle engine, to the AC system and to the body shape of the vehicle. The data are displayed according to the engine size, the fuel type, the vehicle size, the type of compressor and the type of regulation. In order to get enough data per class, only 4 types of vehicles are distinguished (see Table 1). The results show that the fuel consumptions are quite close with large standard deviations. Therefore we assume that the fuel consumption of $\mathrm{AC}$ does not depend on technical parameters.

The climatic conditions and set temperature have certainly a huge influence on AC running, and then on pollutants emissions. No experimentation is performed according to the solar radiation, although, according to Barbusse et al. (1998), solar load represents $45 \%$ of the total load of the air conditioning. Theoretically, the relation between fuel consumption and outside temperature is quite linear because of convective heat gains linearly linked with the difference between outside and inside temperatures. According to the data, the variation of excess fuel consumption with the outside temperature is lower than expected: although the uncertainty of the measurements, the outside temperature at which there is no cooling or heating, obtained by linear extrapolation, seems to be below $0^{\circ} \mathrm{C}$. That seems to demonstrate that $\mathrm{AC}$ is running quite close to full load for the tests, i.e. for outside temperature higher than $28^{\circ} \mathrm{C}$. An extrapolation of these data is therefore non applicable. In addition, as the experiments do not allow us to take into account solar heat radiation, 
a physical model is therefore developed.

\section{2 - Air conditioning physical modelling}

The physical phenomena taken into account are the heat exchanges of the cabin with outdoor, the heat exchange on evaporator of air conditioner, the air conditioner and the engine running.

The passenger compartment modelling is based on a description of heat exchange as it is usually done in mono-zone thermal building modelling (Bolher et al., 2000). Air temperature and humidity in the cabin is assumed to be uniform. Heat exchanges governing temperature of cabin are due to the global heat exchange coefficient, UA $\left(\mathrm{W} \cdot \mathrm{m}^{-2} \cdot \mathrm{K}^{-1}\right)$, the untreated air flow rate due to permeability, $m_{p}\left(\mathrm{~kg} \cdot \mathrm{s}^{-1}\right)$, the internal heat gains due to occupants and electrical equipments, $A_{\text {int }}$ (W), the solar gains, $\mathrm{A}_{\text {sol }}(\mathrm{W})$, and the treated air flow, $\mathrm{m}_{\mathrm{t}}\left(\mathrm{kg} \cdot \mathrm{s}^{-1}\right)$.

The modelling of solar gains (Fraisse \& Virgone, 2001) depends on the direct and diffuse solar radiation, the position of the sun in sky and the geometric and physical properties of the vehicle window. Temperature and flow rate of treated air flow are regulated in order to maintain cabin air temperature to set temperature.

The thermal mass of the vehicle's interior has an effect in dynamic behaviour, increasing cooling demands during cool down for instance, but has no effect during steady state cooling. Weilenmann et al. (2004) have studied initial cool down, by combining the effect of initial cool down of the overheated passenger compartment and the effect of cold start. Two counteracting effects occur: Because of thermal mass, $\mathrm{AC}$ running involves more power than at steady state, and $\mathrm{AC}$ running involves that engine compartment is heated much faster than without AC running. These two effects compensate each other, and excess emission due to initial cool down in comparison to steady state emission is in the same order of magnitude than the cold start excess emission in the same temperature conditions. The thermal mass of the vehicle's interior is therefore neglected.

With the internal temperature $T_{\text {int }}$, the temperature of treated air $T_{t}$, and the outside temperature $T_{\text {ext }}$, the conservative equation of energy is: 


$$
\left(m_{t}+m_{p}\right) \cdot T_{\mathrm{int}}-\left(m_{t} \cdot T_{t}+m_{p} \cdot T_{\text {ext }}\right)=A_{\mathrm{int}}+U A \cdot\left(T_{\text {ext }}-T_{\mathrm{int}}\right)+A_{\text {sol }}
$$

The internal temperature is chosen according to the thermal comfort theory (Fanger, 1972). The conditions of thermal comfort are a combination of skin temperature and body's core temperature providing a sensation of thermal neutrality and the fulfilment of body's energy balance. From ASHRAE standard 55 (1992) and Charles (2003), $23^{\circ} \mathrm{C}$ is chosen as default value. The sensible heat exchange $\mathrm{P}_{\text {sens }}$ at evaporator to maintain internal temperature at the comfort temperature can be deduced, and, if air treated rate $m_{t}$ is known, air treated temperature $T_{t}$ can be calculated:

$$
P_{\text {sens }}=m_{t} \cdot\left(T_{\text {ext }}-T_{t}\right)=\left(m_{t}+m_{p}+U A\right) \cdot\left(T_{\text {ext }}-T_{\text {int }}\right)+A_{\text {sol }}+A_{\text {int }}
$$

Heat exchange at the evaporator can cause dehumidification of air treated. The average surface temperature humidity of air treated across AC evaporator depends on the heat transfer coefficients of evaporator and the temperature of coolant. With the air side heat exchange efficiency, it allows us to calculate the average surface temperature and humidity of outlet air. With assumption on a minimum air flow rate of $300 \mathrm{~m}^{3} / \mathrm{h}$ and a minimum average surface temperature of $0^{\circ} \mathrm{C}$, the air treated temperature can be calculated. We assumed that the efficiencies of AC and engine are constant. For energy efficiency of the engine, experimental data show that running conditions of the engine have a small effect on $\mathrm{CO}_{2}$ emissions due to air conditioning. According to Park et al. (1999), the main parameters on AC efficiency are the temperature conditions, but the effects of temperature on energy efficiency are lower than on cooling demands.

The model is applied to all experimental conditions presented in section 1, and in addition given by Weilenmann et al. (2004), with temperature range resp. of $28-40^{\circ} \mathrm{C}$ and $13-37^{\circ} \mathrm{C}$. The results of the model are compared to the experimental results (see Figure 2). They are quite close for temperature higher than $30^{\circ} \mathrm{C}$. From $20^{\circ} \mathrm{C}$ to $30^{\circ} \mathrm{C}$, the model underestimates the fuel consumption; And below $20^{\circ} \mathrm{C}$, hourly fuel consumption from model are null, but experimental excess fuel consumption can be linked to the electrical consumption of ventilation to prevent condensation of humid air on cold windshields at low outside temperatures.

A second comparison is done with the Mobile 6 model of demand factor based on experimental 
measurements. Demand factor is defined by Mobile 6 as the fraction of running time of AC, but can be also defined as the ratio of part load power consumption to the full load power consumption, estimated at $0.85 \mathrm{l} / \mathrm{h}$. The Mobile 6 model and the proposed model are applied with hourly weather data of Seville in Spain, which has the closest climate in Europe to the climate of Denver where vehicle were followed in order to determine demand factor in Mobile 6. In order to take into account the solar loads, Mobile 6 distinguishes daytime and night, and our model calculates the solar loads for each climatic condition described in the weather data. As shown Figure 3, demand factors obtained by Mobile 6 and our model are quite close for temperature higher than $20^{\circ} \mathrm{C}$. Below $20^{\circ} \mathrm{C}$, demand factor from Mobile 6 model is null but slightly above 0 for our model because of solar loads heating.

We consider that the model satisfied our objective, which is to determine hourly fuel consumption in non-tested weather conditions. The differences between results from model and data from EMPA (Figure 2) at temperature below $20^{\circ} \mathrm{C}$ are not modelled and required additional experiments at these particular conditions.

\section{Simplified model and weather data}

A physical model of excess fuel consumption due to $\mathrm{AC}$ seems to be too complex to be implemented in an inventory software as Artemis. Therefore we computed the physical model with weather data of 91 regions all over Europe. Then by statistical regressions we looked for a relationship between calculated hourly fuel consumption and the following explicative variables: ambient temperature, humidity, position of sun in the sky, and solar radiation, replaced by the hour in the day. The general form of the simplified model is:

$$
h f c=a_{1, w f}+a_{2, w f} \cdot T_{e x t, w f}+a_{3, w f} \cdot T_{\mathrm{int}}+a_{4, w f} \cdot h+a_{5, w f} \cdot h^{2} \quad \text { with } h f c \geq 0
$$

with:

hfc: $\quad$ hourly excess fuel consumption $(1 / h)$

$\mathrm{T}_{\text {ext,wf: }} \quad$ external temperature provided by hourly, daily or monthly weather data $\left({ }^{\circ} \mathrm{C}\right)$, which contain resp. 8760,365 and 12 values 
$\mathrm{T}_{\text {int }}$ : $\quad$ set temperature in the cabin $\left({ }^{\circ} \mathrm{C}\right)$; default value is $23^{\circ} \mathrm{C}$

h: $\quad$ the hour (between 1 and 24)

$\mathrm{a}_{1, \ldots 5, \mathrm{wf}}:$ coefficients depending on the location and the type of weather data

The coefficients $a_{1}$ to $a_{5}$ are available for each of the 91 locations and are specific for hourly, daily or monthly weather data (given in Roujol, 2005). But in addition, two other sets of coefficient a are provided: The first set is given according to 6 modified Köppen climate classification, based on the annual and monthly averages of temperature and precipitation (DOE, 2004), and the second set corresponds to an average: See Table 2.

The excess fuel consumption and $\mathrm{CO}_{2}$ emission for a fleet is calculated by summing hfc according to the number of vehicles with AC running for a given road segment, expressed in number of vehicles per hour.

\section{3 - Excess pollutants emissions analysis}

Data available for pollutant emissions (CO, HC, NOx, PM) due to AC are rare in comparison with data available for $\mathrm{CO}_{2}$ emission, mainly because only 13 gasoline and diesel vehicles are tested.

As it was shown in section $1, \mathrm{AC}$ system is running quite close to the full load at the test conditions (outside temperature $>28^{\circ} \mathrm{C}$ ), where pollutants emissions are assumed to be full load ones. An example of data is shown in Figure 4: NOx emission and effect of AC are larger during the urban driving cycle ECE15 than during the extra-urban cycle EUDC. For each pollutant a relationship is proposed between excess emission and hot emission without AC (see an example on Figure 4). Results of gasoline vehicles are in accordance with the theoretical explanation proposed by Soltic \& Weilenmann (2002): as long as the increased torque does not cause a air fuel mixture enrichment, an increase in the exhaust temperature, a slight reductions of $\mathrm{HC}$ and $\mathrm{CO}$ emissions, and an increase of NOx emission are expected. If an increased torque level causes an increase of enrichment, CO and $\mathrm{HC}$ emissions will also increase.

For the pollutants emissions modelling, we assume that pollutants emissions at part load are a fraction of pollutant emissions at full load, with a fraction equal to the demand factor. 
Because of the lack of data, only a distinction between the gasoline and diesel vehicles is proposed. The model do not explicitly distinguish the age of vehicle, because we consider it has no influence on excess $\mathrm{CO}_{2}$ emission. The effect of emission standard on pollutant emission is taken into account through the hot emission, which depends on standard emission.

For the future vehicles, some counteracting effects occur: Firstly, technological improvements of efficiency of AC system are expected:

- By reducing the thermal load of the vehicle (Türler et al., 2003; Farrington et al., 1998, 1999) through the use of advanced glazing which reduces the transmission of infrared solar radiation. The improvement of air cleaning allows reducing the amount of outside air, reducing by the way thermal load and power consumption of fan. Advanced regulation of ventilation allows ventilating parked vehicles reducing the peak cooling load.

- By increasing energy efficiency ratio of AC system (Benouali et al., 2002; Barbusse \& Gagnepain, 2003). The first improvement will be due to the improvement of AC components as the external control of compressor, the electrical compressor, a high efficiency heat exchanger. At long term, alternative technologies are investigated as magnetic cooling, desiccant cooling, and absorption.

Secondly, the evolution in the vehicle design and in the leakage refrigerant standard will certainly increase the $\mathrm{CO}_{2}$ emission due to the use of $\mathrm{AC}$. For instance, the window area is continuously increasing, and the number of electrical equipments (as GPS and video screen) in passenger compartment is also increasing. The constraint against refrigerant leakage drives to use alternative refrigerant with a lower Global Warming Potential as $\mathrm{HFC} 152 \mathrm{a}$ and $\mathrm{CO}_{2}$. These alternative refrigerants have the drawback to reduce the efficiency of AC system because their lower thermodynamic properties. The use of alternative refrigerant as the $\mathrm{CO}_{2}$ allows using $\mathrm{AC}$ system as a heat pump in order to warm passenger compartment. Currently, the warming of passenger compartment is done by thermal losses of the engine, but the development of high efficiency engine could reduce the possibility to use the engine heat to warm the passenger compartment and justifies the development of reversible system. 
At short time, we assume that these two effects compensate each other. No correction is proposed for future vehicles.

\section{4 - Other auxiliaries}

The excess fuel consumption due to other auxiliaries can be express in $1 / \mathrm{h}$ as for AC. According to Soltic \& Weilenmann (2002), we evaluated an average excess fuel consumption of 0.075 1/h for an electrical load of $160 \mathrm{~W}$ corresponding to dip headlight.

We assume that excess fuel consumption is proportional to electrical load of each auxiliary. In order to be in accordance with excess pollutant emission due to $\mathrm{AC}$, we proposed to use a similar way for excess emission due to auxiliaries. Excess pollutant emission due to $\mathrm{AC}$ at a given conditions is a fraction to excess pollutant emission at full load. This fraction is calculated as a ratio of excess fuel consumption at given condition to excess fuel consumption at full load. We proposed to use the same model by replacing the excess fuel consumption of AC by the excess fuel consumption of auxiliaries. For instance, in the case when headlights are use, the value of fraction is $0.075 / 0.85$.

\section{Conclusion}

The different analyses show that the excess fuel consumption expressed in $1 / \mathrm{h}$ is quite independent to the speed or to the traffic situation. No significant technological parameters are found. That does not mean that no relation exists between excess fuel consumption and technological parameters, but that the number of data is not sufficient to extract this type of relation or that the technological solutions are too close each other.

The excess fuel consumption due to air conditioning is well know in warm conditions because of the large number of experiments. It is quite different in usual climatic conditions with solar radiation, because of the reduced number of experiments. To approach the behaviour of AC system at these conditions, a physical model is proposed and compared to experimental data. According to the objective of the model, the results show a good agreement in warm conditions. At usual conditions, the model underestimates the excess fuel consumption without understanding the 
reason. This model is similar to Mobile 6 but takes account more in detail the climatic conditions. Beside this model, a simplified model is proposed for 90 European regions, based on the full model. It is a part of the new European emission inventorying modelling system Artemis.

Effect of air conditioning in usual conditions is an important way of investigation because of the occurrence of these conditions in comparison to warm conditions. In the model, based on the usual comfort theory, we assume that the set temperature is $23^{\circ} \mathrm{C}$ for all the vehicles equipped with $\mathrm{AC}$, but experiments on real world vehicles with air conditioning could improve the knowledge of user's behaviour.

\section{Acknowledgments}

The authors wish to thank the European Commission for its financial support within the framework of the Artemis research contract $\mathrm{n}^{\circ} 1999-\mathrm{RD} .10429$ "Assessment and reliability of transport emission models and inventory systems"- Project funded by the European Commission under the Competitive and sustainable growth programme of the 5th framework programme.

\section{References}

ASHRAE, 1992 (American Society of Heating Refrigerating and Air Conditioning Engineers): Thermal environmental conditions for human occupancy, ASHRAE standard 55-1992.

Barbusse S., D. Clodic \& J.-P. Roumegoux, 199: Climatisation automobile, énergie et environnement (Automobile air conditioning, energy and environment). Recherche Transport Sécurité, nº60, p. 3-18.

Barbusse S. \& L. Gagnepain, 2003: La climatisation automobile, impact énergétique et environnemental (Automobile air conditioning, impact on the energy consumption and the environment). Données et Références, Ademe, Paris.

Benouali J, D. Clodic \& C. Malvicino, 2002: External and internal control compressors for mobile airconditioning systems. Proc. Int. Refrigeration and air conditioning conf., Purdue, West Lafayette, Indiana, 16-19 July.

Benouali J., D. Clodic, S. Mola, G. Lo Presti, M. Magini \& C. Malvicino, 2003: Fuel consumption of Mobile air conditioning - Method of testing and results. Earth Technology Forum, Washington DC, April 2003, $10 \mathrm{p}$. 
Bolher A., R. Casari, B. Collignan, E. Fleury, D. Marchio, J.R. Millet \& O. Morisot, 2000: Méthode de calcul des consommations des bâtiments climatisés ConsoClim (Method for calculating energy consumption of building with air conditioning ConsoClim). Rapport CSTB/ENEA, DDD/CVA-99-176R, Marne-la-Vallée, France.

Charles K.E., 2003: Fanger's Thermal comfort and draught models. Institute for Research in Construction, IRC RR 162 report, Ottawa, Canada, 29 p.

DOE - Department of Energy, 2004: EnergyPlus. Washington. Available from: http://www.eren.doe.gov/buildings/energy tools/energyplus/

ECCP, 2003: How to considerably reduce greenhouse gas emissions due to mobile air conditioners. Consultation paper, European Commission, DG Environment, Brussels.

Fanger P.O. (1972): Thermal comfort. McGraw-Hill Book.

Farrington R.B, D.L. Brodt, S.D. Burch \& M. A. Keyser, 1998: Opportunities to reduce vehicle climate control loads. Proc. $15^{\text {th }}$ Electric Vehicle Symp., Brussels, Sept. 30-Oct. 3.

Farrington R.B., R. Anderson, D.M. Blake, S.D. Burch, M.R. Cuddy, M. A. Keyser \& J.P. Rugh, 1999: Challenges and potentials solutions for reducing climate control loads in conventional and hybrid electric

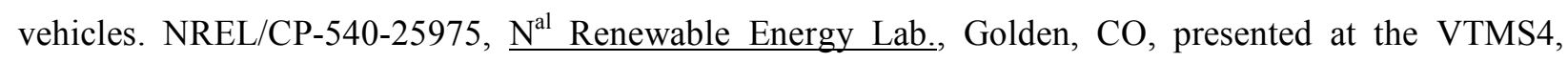
London, May 26, 1999.

Fraisse G. \& J. Virgone, 2001: Modélisation numérique d'un bâtiment multizone sous TRNSYS (Numerical modelling of a multizone building with Trnsys). 4es Journées TRNSYS Francophones, Lyon, France, 10 Sept. 2001, 19 p.

Gense N. L. J., 2000: Driving style, fuel consumption and tail pipe emissions - Final report. TNO report, Delft, the Netherlands.

Hugrel C. \& R. Joumard, 2004: The contribution of passenger cars to the greenhouse effect : influence of airconditioning and ACEA's commitment (JAMA and KAMA included) on the $\mathrm{CO}_{2}$ emissions. Proc. 13th Symp. Transport and Air Pollution, Boulder, USA, Sept. 13-15, 2004, NCAR ed., Boulder, p. 305-313. $\underline{\text { www.inrets.fr/ur/lte/publi-autresactions/notedesynthese/notehugrel.html }}$

Koupal J.W., 2001: Air Conditioning Activity Effects in MOBILE6. M6.ACE.001, USEPA.

Koupal J.W. \& J. Kremer (2001): Air Conditioning Corrections Factors in MOBILE6. M6.ACE.002 USEPA.

Park Y.C., R. McEnaney, D. Boewe, J.M. Yin \& P.S. Hrnjak, 1999: Steady state and cycling performance of 
a typical R134a Mobile A/C System. SAE paper, 1999-01-1190, Warrendale, USA.

Pelkmans L, G. Lenaers, P. Debal, M. Van Poppel, T. Hood, G. Hauser \& M. R. Delgado, 2003: Impact of air conditioning, ambient temperature and humidity on emissions of modern passenger cars. Proc. $12^{\text {th }}$ Symp. Transport and Air Pollution, Avignon, France, June 16-18, 2003, vol. 2,Inrets ed. Arcueil, France, p. $145-152$.

Roujol S., 2005: Influence of passenger car auxiliaries on pollutant emissions - Artemis 324 report. Inrets report, LTE 0502, Bron, France, 56 p.

www.inrets.fr/ur/lte/publications/publications-pdf/Joumard/A324reportSRLTE0502.pdf

Roumégoux J-P., M. André, R. Vidon, P. Perret \& P. Tassel, 2004: Consommation de carburant et émission de $\mathrm{CO}_{2}$ des auxiliaires : climatisation et alternateur, impact des optimisations (Fuel consumption and $\mathrm{CO}_{2}$ emission due to auxiliaries: air conditioning, alternator, impact of optimisations). Rapport INRETS, $n^{\circ}$ LTE 0428, Bron, France, 28 p.

Soltic P. \& M. Weilenmann, 2002: Influence of electric load on the exhaust gas emissions of passenger cars. Proc. $11^{\text {th }}$ Symp. Transport and Air Pollution, Graz, Austria, June 19-21, 2002, TUG ed., Graz, p. 179186.

Türler D., D. Hopkins \& H. Goudey, 2003: Reducing vehicle auxiliary loads using advanced thermal insulation and window technologies. SAE paper, 2003-01-1076, in Advances in Automotive Climate Control Technologies, SP-1733, Warrendale, USA.

Weilenmann M., A.M. Vasic \& P. Stettler, 2004: Effect of air conditioning activity on fuel consumption and CO2 emissions in Europe. Proc. 13th Symp. Transport and Air Pollution, Boulder, USA, Sept. 13-15, 2004, NCAR ed., Boulder, p. 395-402. 
Figure 1: Excess fuel consumption $(1 / \mathrm{h})$ due to $\mathrm{AC}$ versus average speed $(\mathrm{km} / \mathrm{h})$, with polynomial regression.

Figure 2: Comparison of the modelled and experimental hourly excess fuel consumption as a function of outside temperature for two internal temperatures $\left(20\right.$ and $\left.23^{\circ} \mathrm{C}\right)$.

Figure 3: Comparison of the demand factor as modelled by Mobile 6 (upper almost continuous curve for daytime and lower almost continuous curve for night) and by the proposed model (scatter plot). Set temperature at $23^{\circ} \mathrm{C}$.

Figure 4: NOx excess emission versus NOx emission AC off according to the fuel and driving cycle for Euro 1 vehicles, for urban ECE15 (or UDC) and extra-urban EUDC driving cycles, with the corresponding modelling.

Table 1: $\quad$ Average fuel consumption due to air conditioning $(1 / \mathrm{h})$ for the 4 vehicle types.

Table 2: $\quad$ Values of hourly fuel consumption simplified model for hourly, daily or monthly weather format for 6 modified Köppen climate classes and an average. 


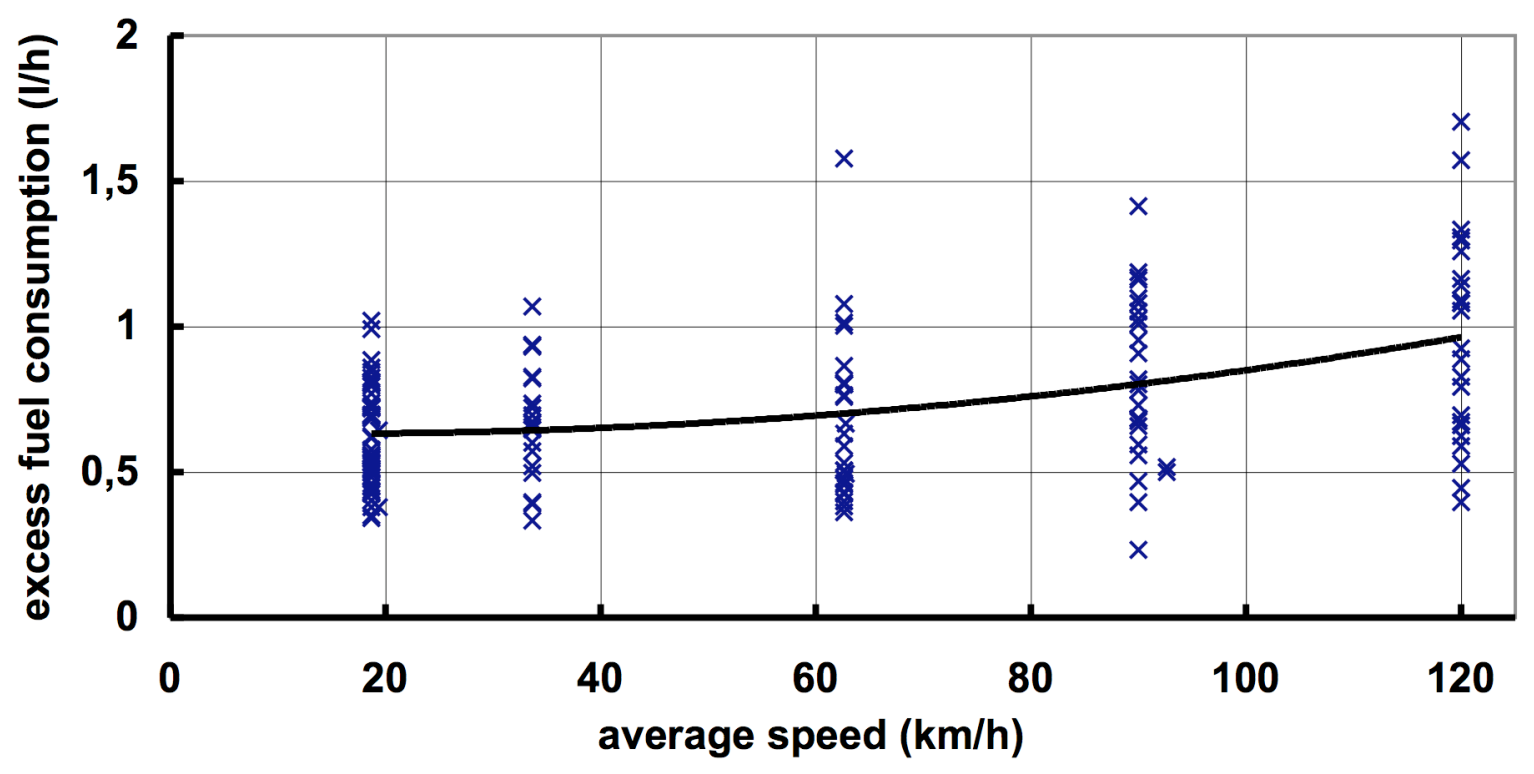

Figure 1: Excess fuel consumption $(1 / \mathrm{h})$ due to $A C$ versus average speed $(\mathrm{km} / \mathrm{h})$, with polynomial regression.

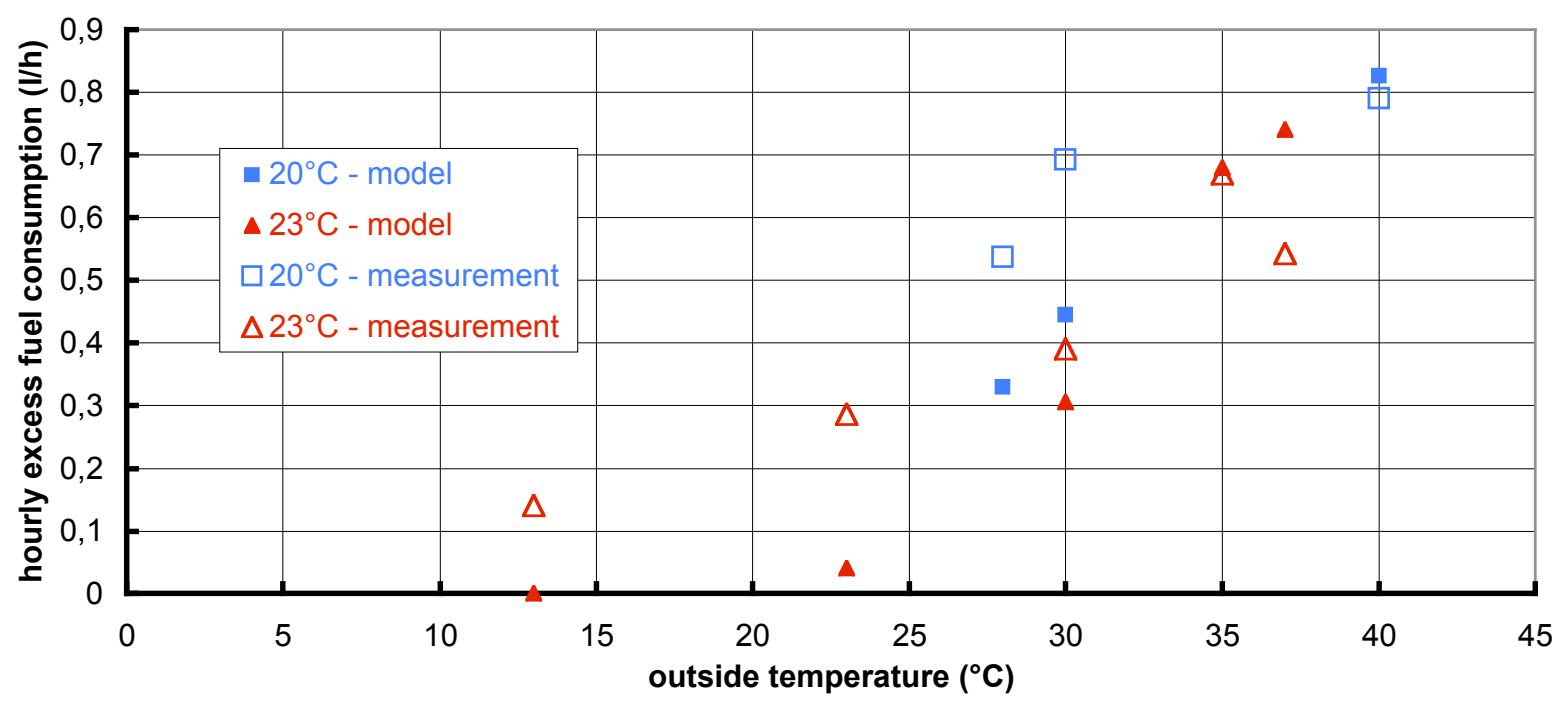

Figure 2: Comparison of the modelled and experimental hourly excess fuel consumption as a function of outside temperature for two internal temperatures $\left(20\right.$ and $\left.23^{\circ} \mathrm{C}\right)$. 


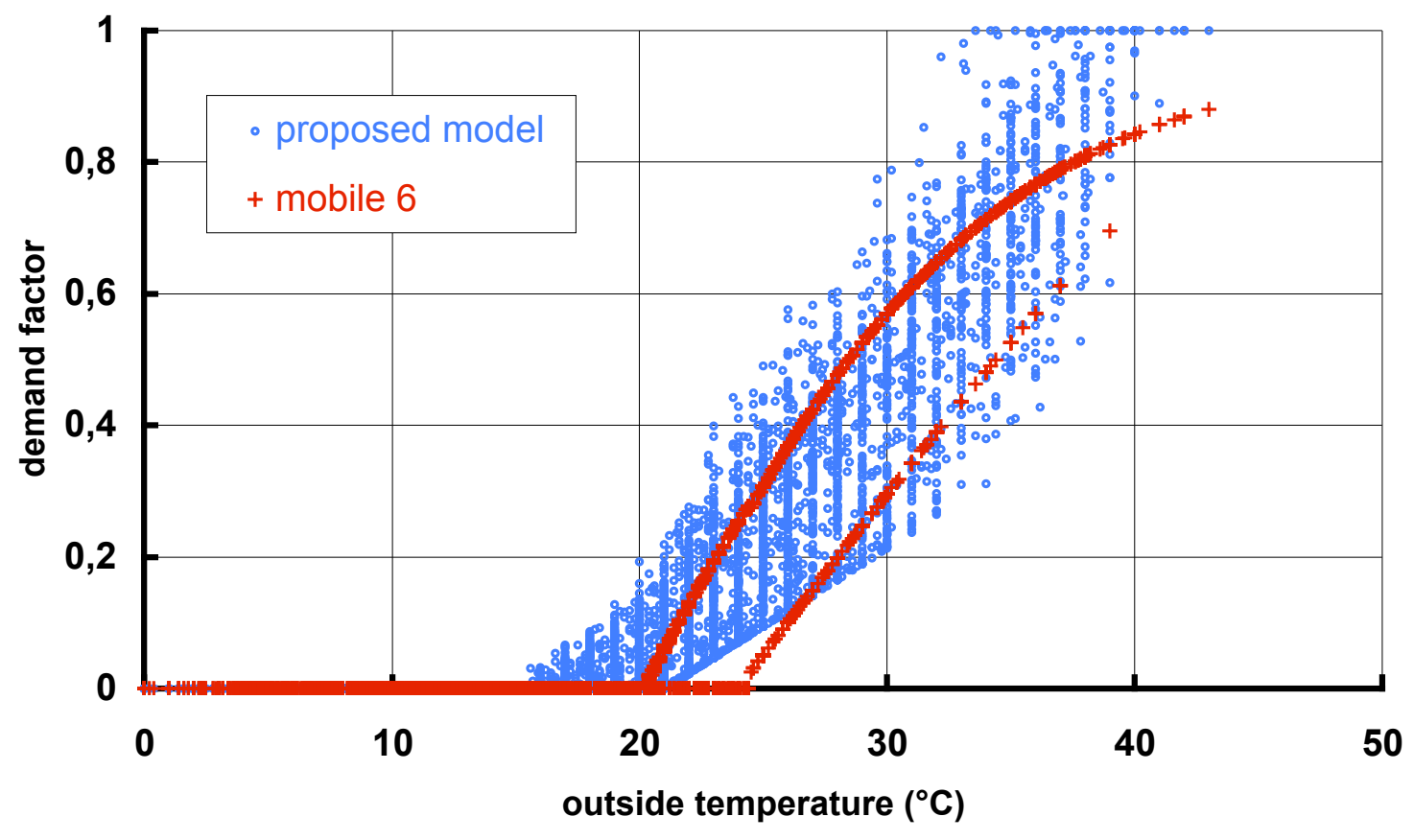

Figure 3: Comparison of the demand factor as modelled by Mobile 6 (upper almost continuous curve for daytime and lower almost continuous curve for night) and by the proposed model (scatter plot). Set temperature at $23^{\circ} \mathrm{C}$.

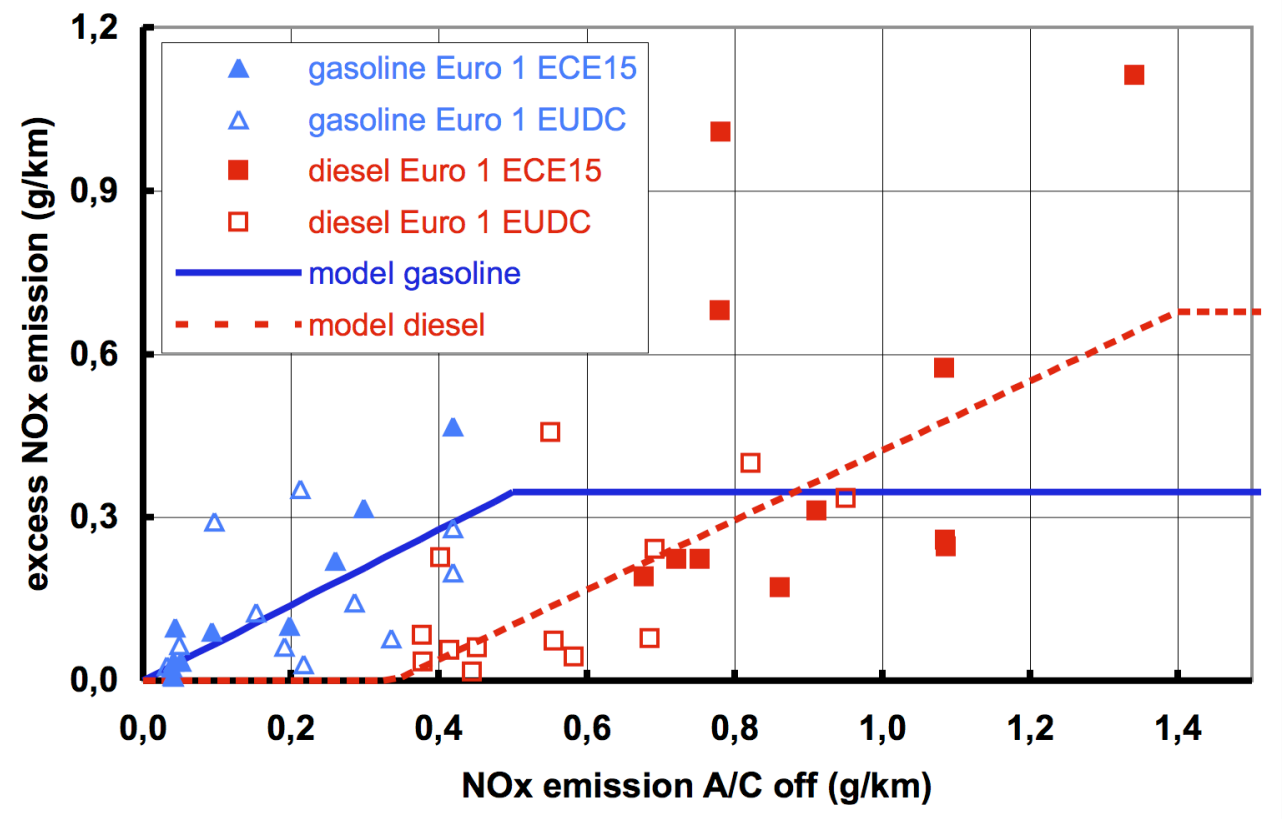

Figure 4: NOx excess emission versus NOx emission AC off according to the fuel and driving cycle for Euro 1 vehicles, for urban ECE15 (or UDC) and extra-urban EUDC driving cycles, with the corresponding modelling. 


\begin{tabular}{|c|c|c|c|c|c|}
\hline \multicolumn{2}{|c|}{ vehicle type } & \multirow{2}{*}{ nber veh.-tests } & \multicolumn{2}{c|}{ fuel consumption } \\
\cline { 5 - 6 } & fuel & AC regulation & & average & st. dev. \\
\hline \multirow{2}{*}{ Small, Medium 1 } & Gasoline & \multirow{2}{*}{ manual } & 38 & 0.7 & 0.2 \\
\cline { 2 - 4 } & Diesel & & 55 & 0.68 & 0.22 \\
\cline { 5 - 6 } & \multirow{2}{*}{ Medium 2, Large, SUV } & Gasoline & 25 & 0.75 & 0.34 \\
\cline { 2 - 4 } & Diesel & & 28 & 0.85 & 0.35 \\
\cline { 4 - 6 }
\end{tabular}

Table 1: $\quad$ Average fuel consumption due to air conditioning $(1 / \mathrm{h})$ for the 4 vehicle types.

\begin{tabular}{|c|c|c|c|c|c|c|}
\hline Type of weather data & Köppen classes & $a_{1}$ & $a_{2}$ & $a_{3}$ & $a_{4}$ & $a_{5}$ \\
\hline \multirow{6}{*}{$\begin{array}{l}\text { hourly } \\
\text { weather } \\
\text { format }\end{array}$} & $\mathrm{Cfa}$ & -1.0368 & 0.0436 & -0.0404 & 0.0455 & -0.00189 \\
\hline & $\mathrm{Cfb}$ & -0.8575 & 0.0343 & -0.0315 & 0.0480 & -0.00202 \\
\hline & Csa/Csb & -0.9618 & 0.0393 & -0.0380 & 0.0482 & -0.00203 \\
\hline & Dfb & -0.7937 & 0.0333 & -0.0319 & 0.0417 & -0.00185 \\
\hline & Dfc & -0.6450 & 0.0242 & -0.0250 & 0.0431 & -0.00181 \\
\hline & average & -0.886 & 0.0363 & -0.0339 & 0.0458 & -0.00195 \\
\hline \multirow{6}{*}{$\begin{array}{c}\text { daily } \\
\text { weather } \\
\text { format }\end{array}$} & $\mathrm{Cfa}$ & -1.1486 & 0.0372 & -0.0352 & 0.0951 & -0.00356 \\
\hline & $\mathrm{Cfb}$ & -1.0914 & 0.0305 & -0.0243 & 0.1032 & -0.00378 \\
\hline & $\mathrm{Csa} / \mathrm{Csb}$ & -1.2800 & 0.0362 & -0.0323 & 0.1205 & -0.00443 \\
\hline & Dfb & -1.1300 & 0.0309 & -0.0267 & 0.1110 & -0.00414 \\
\hline & Dfc & -0.8225 & 0.0203 & -0.0203 & 0.0857 & -0.00313 \\
\hline & average & -1.116 & 0.0322 & -0.0278 & 0.1034 & -0.00382 \\
\hline \multirow{6}{*}{$\begin{array}{l}\text { monthly } \\
\text { weather } \\
\text { format }\end{array}$} & $\mathrm{Cfa}$ & -0.6914 & 0.0264 & -0.0106 & 0.0629 & -0.00233 \\
\hline & $\mathrm{Cfb}$ & -0.3029 & 0.0117 & -0.0046 & 0.0313 & -0.00116 \\
\hline & Csa/Csb & -0.6573 & 0.0244 & -0.0088 & 0.0616 & -0.00226 \\
\hline & $\mathrm{Dfb}$ & -0.2979 & 0.0111 & -0.0051 & 0.0349 & -0.00132 \\
\hline & Dfc & -0.1095 & 0.0041 & -0.0020 & 0.0135 & -0.00050 \\
\hline & average & -0.407 & 0.0155 & -0.0063 & 0.0407 & -0.00151 \\
\hline
\end{tabular}

\begin{tabular}{|c|c|}
\hline Köppen classes & Description \\
\hline $\mathrm{Cfa}$ & $\begin{array}{l}\text { "C" indicates the "mild mid-latitude" type, the second letter "f" comes from the } \\
\text { German word "feucht" which means moist and the last letter "a" indicates that the } \\
\text { average temperature of the warmest month is above } 22^{\circ} \mathrm{C} \text {. }\end{array}$ \\
\hline $\mathrm{Cfb}$ & this climate is similar to Cfa with a cooler warmest month. \\
\hline Csa & $\begin{array}{l}\text { the group of letter "Cs" indicates a Mediterranean climate, "a" indicates that the } \\
\text { average temperature of the warmest month is above } 22^{\circ} \mathrm{C}\end{array}$ \\
\hline Csb & this climate is similar to Csa with a cooler warmest month. \\
\hline Dfb & $\begin{array}{l}\text { "D" indicates a moist continental mid-latitude climates, "f" indicates that the climate } \\
\text { is wet at all seasons and "b" that the average temperature of warmest month is } \\
\text { below } 22^{\circ} \mathrm{C} \text { and average temperature of the } 4 \text { warmest months is above } 10^{\circ} \mathrm{C} \text {. }\end{array}$ \\
\hline Dfc & $\begin{array}{l}\text { This climate is close to Dfb, "c" means that average temperature of } 1 \text { to } 3 \text { warmest } \\
\text { months is above } 10^{\circ} \mathrm{C} \text {. }\end{array}$ \\
\hline
\end{tabular}

Table 2: $\quad$ Values of hourly fuel consumption simplified model for hourly, daily or monthly 
weather format for 6 modified Köppen climate classes and an average. 